\title{
The Effect of Information Asymmetry on Investment Behavior in Cryptocurrency Market
}

\author{
Minjung Park \\ School of Business, \\ Ewha Womans University \\ mjpark67@ewhain.net
}

\author{
Sangmi Chai \\ School of Business, \\ Ewha Womans University \\ smchai@ewha.ac.kr
}

\begin{abstract}
With the increase in the attention to cryptocurrency, studies on the factors affecting the price fluctuation of cryptocurrency have been actively conducted. Prior researches suggested that policy announcements (i.e., public information) related to cryptocurrency have been found to affect the price volatility in the market in particular. Privileged information, which is hard to be observable unlike public information published by the government or corporations, is hardly homogenously distributed to individual investors. However, it inevitably affects the price in any market. Therefore, this study aims to identify the information asymmetry, which is mainly formed by privileged information, in the cryptocurrency market. Moreover, this study examines whether investment sentiment, which mainly influences transaction behaviors of uninformed traders, has a significant effect on the cryptocurrency market as well. The results contribute to the understanding of the cryptocurrency market in a basis of the existing market theories.
\end{abstract}

\section{Introduction}

Bitcoin, blockchain based cryptocurrency, has been attracting attention in the global market for several years; it threatens the position of the existing currency and extends its influence in the market to the extent that it is discussed to possibly replace the existing currency [1]. Along with such popular attention, there has been an increase in the number of traders who regard cryptocurrency, as stocks or assets to buy and sell. Thus, investors try to collect relevant information in advance to maximize profit and minimize loss by predicting the price fluctuation of each cryptocurrency. This loss aversion of investors is mainly derived from the difference in their profits due to information asymmetry in the market. Information asymmetry has existed in the stock market for a long period of time, with the tendency of market participants to believe that homogeneous information is not evenly distributed in the market $[2,3]$.

Information in the market is mainly classified into public information and privileged information by its contents [4]. Public information refers to the information known to all investors at the same time, that affects the stock prices due to the official announcement such as weather, legal antecedents, and all information issued by the governments or companies [5]. Privileged information generated by institutional investors or professional analysts, which is regarded as one of main factors of stock market volatility [6-8], is not open to public officially. Informed traders, on the basis of which they try to obtain excess profits or avoid losses, frequently perform transactions only for speculative purposes, distorting the market. For example, they buy mass amount of stocks before a positive event, or sell a mass amount of stocks before a negative event, in the market. Therefore, informed traders with privileged information tend to maintain an advantageous position to obtain excess profits than uninformed traders.

This study aims to verify an existence of information asymmetry in the cryptocurrency market and identify how it is different from the traditional stock market. It assumes the existence of gap between traders with privileged information and traders without it in the cryptocurrency market. To quantify information asymmetry, we compare the transaction intensity of informed traders and uninformed traders in ten major types of cryptocurrency market.

We also examine the relationship between cryptocurrency price and investment sentiment that affects the transaction behaviors of uninformed traders. Since trading decisions of an uninformed trader is made largely by investment sentiment including personal recognition and bias rather than information, it affects not only the trading behaviors of the trader but also the formation of information asymmetry in the market [9]. Given the above arguments, the following research question is articulated: 
$R Q \quad 1:$ Is information asymmetry in the cryptocurrency market more intense than the traditional stock market?

$R Q$ 2: Is cryptocurrency investors' investment sentiment is related to information asymmetry?

To answer this first research question (i.e., to identify information asymmetry in cryptocurrency market), firstly, we apply the PIN (Probability of Informed Trading) model, which assumes market participants to estimate the true price of stocks market through market transaction information[10]. The PIN model is estimating the intensity of informed traders and uninformed traders through the number of transactions. Secondly, we adopt EPU (Economic Policy Uncertainty) as an alternative proxy for evaluating trader's investor sentiment. Based on EPU index, we figure out whether the price of cryptocurrency is influenced by investor sentiment. To identify a relationship of investor sentiment and cryptocurrency price volatility, this study adopted VECM (Vector Error Correction Model), which is a method for analyzing non-stationary data such as stock or gold price, for a long time.

\section{Literature review}

\subsection{Information asymmetry}

Information efficiency refers that the price determined in the market fully reflects all available information [43]. This information efficiency is achieved when information about stocks are distributed to all investors quickly, fairly and inexpensively and the information is accurately reflected in the price of the stocks [41, 43]. However, information asymmetry is formed when this information is not distributed to all investors fairly in the market. It refers a discrepancy in the volume and accuracy of information held by two or more market participants occurs in terms of a specific event with a huge ripple effect $[11,12]$. Moreover, they may take actions that are beneficial to them but are detrimental to the other investors. asymmetry is difficult to be totally resolved, although information asymmetry in the market can be reduced by external sources of information like financial analysts [13].

Information asymmetry has existed in the market, for a long time, as we above mentioned. Informed traders, may take advantage of their privileged positions of information to earn excess profits. They may take actions that are beneficial to them but are detrimental to the other investors. Asymmetric information, therefore, can often lead to high price fluctuations and, finally it makes to occurs market failure. Information asymmetry has been considered an important factor for evaluating the price stability.
Information asymmetry prevailing in the stock market over a long period of time can be applied to the cryptocurrency market as well, for the following reasons. First, the relatively complicated system of cryptocurrency, which is hard for potential users to understand, is prone to arise the issue of information asymmetry [42]. Information related to cryptocurrency, a digital currency based on the newly emerging blockchain technology [14], has not accumulated yet, investors are likely to have difficulty in collecting or obtaining the desired information in a short time. The lack of various prior cases to appropriately deal with unpredicted situations in the market, and the difficulty in precisely predicting the market issues and incidents related to cryptocurrency, the relevant information cannot be equally distributed. Furthermore, cryptocurrency is also still limited in the discipline of information systems [15], we have a hard to discover a variety of references related on cryptocurrency. Second, disclosure systems (e.g., Corporate Disclosure, Regulation Fair Disclosure, Financial Information Disclosure, Environmental Information Disclosure etc.), the typical means to mitigate information asymmetry among investors, have not yet been systematically organized in the cryptocurrency market. The various disclosure systems are procedures to officially disclose information to investors. As information disclosure level increases, information asymmetry among capital market participants decreases [16-18]. Thus, a disclosure system in the stock market is a decisive component in relieving information asymmetry among investors. However, the absence of mandatory disclosure systems in the cryptocurrency market leaves investors only few formal procedures to obtain credible information on the tokens or coins that they invest in. Cryptocurrency traders are bound to rely only on white papers introducing the cryptocurrency project, or on the opinions of a handful of cryptocurrency experts who review these white papers. ICOs (Initial Coin Offerings), a process to new way to raise funds by issuing a token or coin, is also found to have information asymmetry [19]. The success of the ICOs are determined by the types and amounts of information the participants or traders had acquired [20]. Third, similar to the stock market, the cryptocurrency market is found to reflect the characteristics of market microstructure models, where homogenous information cannot have equally distributed to all investors all the time [21]. Therefore, the formation of information asymmetry in the cryptocurrency market is inevitable from the perspective of the market microstructure that the market is operated through the process of intensifying or mitigating information asymmetry among investors. Based on the discussions above, this study suggests that between the stakeholders with information advantage 
(e.g., cryptocurrency issuers, virtual currency traders, mass holders or miners, blockchain technicians) and general traders with information disadvantage will form information asymmetry, in the cryptocurrency market.

\subsection{EPU (Economic Policy Uncertainty) as a measure for investor sentiment}

Common judgment errors of multiple investors, called as investor sentiment, and their cognitive behaviors are reflected in investment decisions [22]. According to the behavioral finance theory, investors tend to decide investment based on behavioral biases or style investing such as sentiment, stereotype or impulse rather than information events [23]; the existence of an irrational trader who makes decisions by each investor sentiment, not an rational trader, brings about information asymmetry in the market [24]. Investor sentiment is an important factor that affects prices [25], returns [26], price volatility [27] and asset valuation [28]. In addition, more unstable investor's sentiment is associated with greater future volatility [29]. It is expected that uninformed traders, who have failed to acquire enough privileged information in the cryptocurrency market with presumably asymmetrically distributed information, are more likely to decide to invest by 'investor sentiment' than 'information' compared to informed traders.

Among the various measures for investment sentiment, this study uses EPU(Economic Policy Uncertainty) [18], which is a representative proxy for investment sentiment. EPU is an index estimated by dividing the frequency of articles containing all three word categories of Economy, Uncertainty and Policy (ex. congress, deficit, Federal Reserve, legislation, regulation, White House, etc.) by the total number of articles $[30,31]$. For example, the US EPU index has been measured from 1985 to the present by the coverage frequency in 10 major newspapers, including Boston Globe, Chicago Tribune, LA Times, New York Times and USA Today. The EPU Index of 18 major countries including Europe, South Korea, Japan, and China was updated every month, focused by the representative newspaper reports of each country [26, 30]. A number of previous studies have evaluated EPU as a representative alternative proxy for investor sentiment [32]. As it turned out that Bitcoin is also affected by EPU [33] and EPU has a predictive power on the Bitcoin returns [34], finally, it can be concluded EPU is appropriate to measure investor sentiment. This study obtained the EPU Index data of the United States, Japan, China, Korea, Europe, and Singapore at http://www.policyuncertainty.com, from August 2015 to March 2019, when the cryptocurrency-related data was collected. Based on the collected data, this study attempts to identify information asymmetry in the cryptocurrency market by exploring whether the influences of EPU of each country on the price of the cryptocurrency varied during the given period.

\section{Data collection}

As discussed above, this study has a main objective to identify information asymmetry among investors in the cryptocurrency. From August 7, 2015 to March 31, 2019 , transactions data of ten types of cryptocurrency for a total of 1333 days were collected regarding market price, closing price, trading volume. The stability of the ten selected types of cryptocurrency, including Bitcoin, was confirmed in that they have been traded on the market for a relatively long time since 2015 . Thus, such long-term transactions data collection had a strong advantage in increasing the accuracy of the evaluation results. In this study, information asymmetry, which had been formed in cryptocurrency market, were estimated by the amount of ask and bid on the day based on closing price. Table 1. shows the details of the cryptocurrency types and transactions data.

Table 1. Data description

\begin{tabular}{|c|c|c|c|}
\hline Type (Code) & Mean Close Price & Total Volume & Market Cap (Total Rank) \\
\hline Bitcoin (BTC) & $3,603.447$ & $3,121,008,281,873$ & $67,869,142,978(1)$ \\
\hline Ethereum (ETH) & 210.722 & $1,109,053,097,460$ & $14,421,516,939(2)$ \\
\hline Dash (DASH) & 174.225 & $77,219,841,709$ & $732,446,863(15)$ \\
\hline XRP (XRP) & 0.258 & $403,338,441,990$ & $13,279,830,678(3)$ \\
\hline Monero (XMR) & 72.774 & $37,139,045,679$ & $833,562,952(13)$ \\
\hline Litecoin (LTC) & 47.259 & $293,998,718,099$ & $2,893,094,415(5)$ \\
\hline Stellar (XLM) & 0.094 & $50,121,669,758$ & $1,636,735,921(8)$ \\
\hline NEM (XEM) & 0.141 & $16,719,467,626$ & $386,987,466(19)$ \\
\hline Thether (USDT) & 1.000 & $1,185,662,543,005$ & $2,037,684,692(7)$ \\
\hline Dogecoin (DOGE) & 0.002 & $12,122,868,444$ & $235,330,582(25)$ \\
\hline
\end{tabular}




\section{Research method}

\subsection{PIN (Probability of Informed Trading)}

The PIN model shows the ratio of informed transactions to the total trading volume during a single day. Unlike other information asymmetric measurement models, the PIN model, which measures transaction data, has the advantage of measuring only information asymmetry regardless of other considerations such as order processing cost $[10,35]$. It estimates the intensity of informed traders and, uninformed traders, which are not directly observable in market, by using observable data of the numbers of ask and bid transactions. The estimation is based on the following assumptions: first, as a transaction begins, the occurrence of an information event related to firm value is expressed as probability $\alpha$. Second, whether the information even occurs as bad news or good news is determined by the probability of $\delta$ and $1-\delta$, respectively. Third, the participants' transactions happen during a day follows the Poisson distribution [36]. In this process, since an informed trader already knows the information, he or she chooses to buy only for good news, and sell only for bad news. Thus, in the PIN model, the normal range of selling and buying is interpreted as an uninformed trading, while the abnormal range of selling and buying is interpreted as informed trading. Therefore, the probability that a trader conducts a transaction based on information is defined as $\mu$, and the probability that an uninformed trader buys and sells is $\varepsilon_{\mathrm{b},} \varepsilon_{\mathrm{s}}$, respectively. The PIN model is presented in Figure 1.

As mentioned above, given that privileged information cannot be observable directly market, the estimates of the defined parameters in the PIN model are based on Maximum Likelihood Estimation. Thus, the PIN model shows the proportion of the transactions by informed traders during a day.

$$
P I N=\frac{\alpha \mu}{\alpha \mu+\varepsilon_{S}+\varepsilon_{b}}
$$

In other words, it can be explained as the next equation.

$$
P I N=\frac{\text { Expected number of trades per day by informed traders }}{\text { Expected total number of trades per day }}
$$

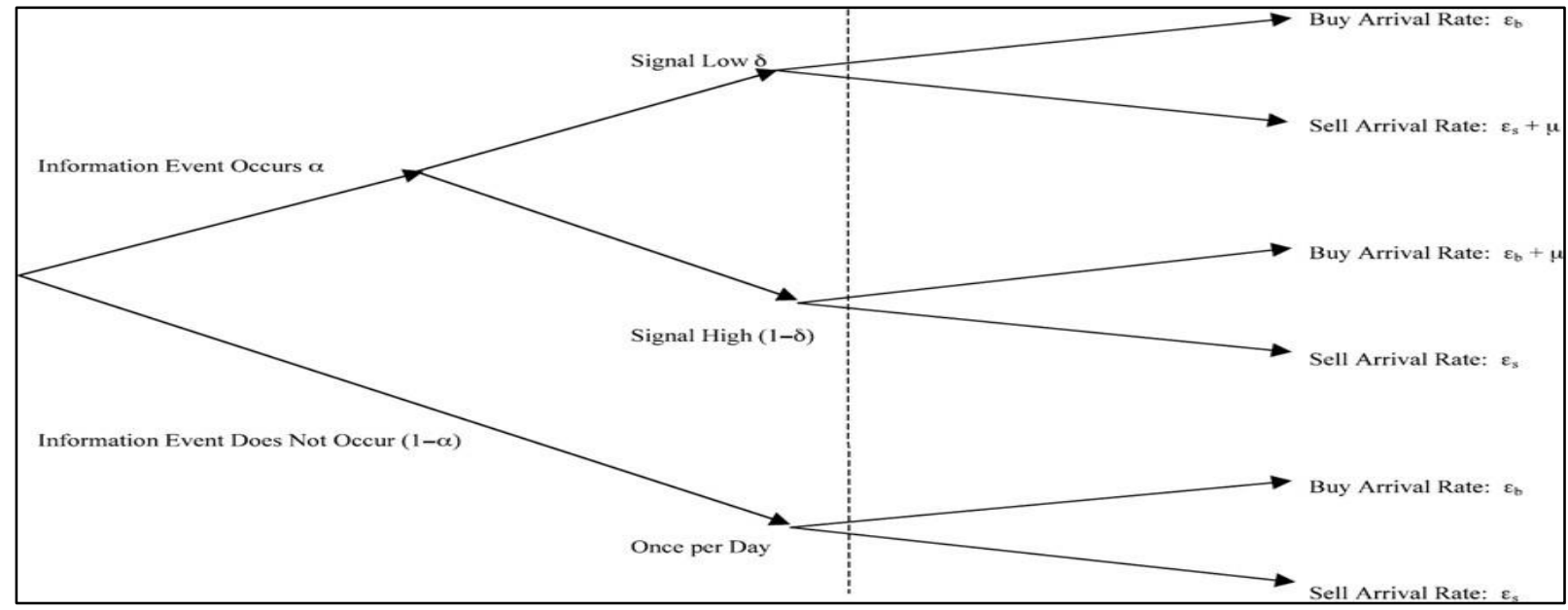

Figure 1 Tree diagram of the trading process [35]

\subsection{VCEM (Vector Error Correction Model)}

Most macroeconomic variables represent nonstationary time series [37]. Therefore, when unstable time series have a cointegration relationship, VECM is suitable for verifying long-term equilibrium relationship between time series variables and short-term dynamic structure relationship; because the model can gradually corrects the part where the long-term equilibrium is deviated through a short-term adjustment process [38]. Therefore, VECM allows for distinguishing long-term and short-term causal relationships between variables [39]. In particular, VECM is distinctive the VAR model, which mainly represents short-term dynamics. VECM is highly useful for dynamically analyzing the interrelation of unstable time series variables. In case of having two or more variables, the VECM equation is as follows.

$$
y_{t}=\alpha_{1} y_{t-1}+\cdots+\alpha_{p} y_{t-p}+\beta x_{t}+e_{t}
$$




\section{Results}

\subsection{Information asymmetry - PIN}

This study estimated information asymmetry from ten types of cryptocurrency transaction data collected for approximately 3 years. The results can be summarized; first, in terms of the intensity of informed traders during the data collection period, DASH was the highest (27\%), whereas XEM was lowest (8\%).
Therefore, it was confirmed that XEM, which had the highest proportion of uninformed traders, formed the largest information asymmetry in the market. Specifically, the probability of an information event occurrence related to XEM was approximately $9 \%$ in the market, of which the probability of bad news was $56 \%$. Following XEM, USDT, DOGE, and XMR in order formed information asymmetry in the market. The analysis results of information asymmetry of each cryptocurrency are shown in Table 2 in detail.

Table 2. Results of PIN analysis

\begin{tabular}{|c|c|c|c|c|c|c|}
\hline Code & $\begin{array}{c}\text { News } \\
\text { probability }(\alpha)\end{array}$ & $\begin{array}{c}\text { Probability of } \\
\text { bad news }(\delta)\end{array}$ & $\begin{array}{c}\text { Informed } \\
\text { trading } \\
\text { intensity }(\mu)\end{array}$ & $\begin{array}{c}\text { Uninformed } \\
\text { trading intensity } \\
- \text { Buy }\left(\varepsilon_{b}\right)\end{array}$ & $\begin{array}{c}\text { Uninformed } \\
\text { trading intensity } \\
- \text { Sell }\left(\varepsilon_{s}\right)\end{array}$ & PIN (Rank) \\
\hline BTC & 0.36 & 0.64 & $4,433,197,159$ & $387,969,399$ & $387,969,399$ & $23.3 \%(3)$ \\
\hline ETH & 0.38 & 0.36 & $1,598,670,439$ & $322,742,903$ & $322,742,903$ & $26.2 \%(2)$ \\
\hline DASH & 0.39 & 0.19 & $95,589,656$ & $28,154,636$ & $28,154,636$ & $26.9 \%(1)$ \\
\hline XRP & 0.19 & 0.54 & $89,582,319$ & $75,933,812$ & $7,613,894$ & $14.7 \%(6)$ \\
\hline XMR & 0.36 & 0.53 & $718,114,298$ & $7,613,894$ & $75,933,812$ & $14.5 \%(7)$ \\
\hline LTC & 0.32 & 0.77 & $2,050,790,971$ & $75,933,812$ & $40,389,190$ & $22.2 \%(4)$ \\
\hline XLM & 0.22 & 0.62 & $122,323,844$ & $40,389,190$ & $8,562,034$ & $1.7 \%(5)$ \\
\hline XEM & 0.09 & 0.56 & $1,837,153,511$ & $8,562,034$ & $90,928,064$ & $7.7 \%(10)$ \\
\hline USDT & 0.99 & 0.50 & $68,204,460$ & $3,339,519$ & $3,339,519$ & $8.6 \%(9)$ \\
\hline DOGE & 0.11 & 0.57 & $43,775,805$ & $2,533,923$ & $2,533,923$ & $9.5 \%(8)$ \\
\hline
\end{tabular}

\subsection{Comparison of information asymmetry}

We compared the level of information asymmetry between the cryptocurrency market and the traditional stock market. Table 3 shows previous research results of information asymmetry estimated through the PIN model for major stock markets. In order to compare the information asymmetry level between cryptocurrency market and the stock market, 'Day PIN' was additionally examined. Day PIN value indicates that the probability of informed traders investing on cryptocurrency based on their own privileged information for one day. 'Day PIN' is applied to resolve the difference in analysis period of two the comparative samples. The results of the previous studies of the comparison subjects also use the PIN value which is estimated on a day basis.

Table 3. Information asymmetry

\begin{tabular}{|c|c|c|c|}
\hline Subject & Day PIN & Period & Description \\
\hline Cryptocurrency & $11.7 \%$ & Aug. 07, $2015 \sim$ Mar.31, 2019 & 10 major types of cryptocurrencies \\
\hline Hong Kong Stocks [51] & $12.5 \%$ & Jan. 01, $2003 \sim$ Dec. 31, 2003 & $\begin{array}{c}200 \text { stocks in Hong Kong Composite } \\
\text { Index (HSHKCl) }\end{array}$ \\
\hline US Stocks [48] & $22.5 \%$ & Nov. 01,1990 Jan. 01, 1991 & 144 stocks in the US \\
\hline Korean Stocks [52] & $18.0 \%$ & Jan. 01, $2002 \sim$ Mar. 31, 2002 & 416 stocks in Korea \\
\hline
\end{tabular}


As a result, 'DAY PIN' of the cryptocurrency market was found to be smaller than Hong Kong, US and Korean stock market. In other words, it can be inferred that there are many investors who decide to invest based on privileged information in the current cryptocurrency market, compared to the others. These results show that privileged information has a considerable influence on the current cryptocurrency market, and it can be deduced that privileged information can distort the market or move the price volatility drastically. This study results indicate the effect of the risks associated with privileged information in the cryptocurrency market.

\subsection{Unit root test}

The first step of a time series analysis is a unit root test to determine whether all-time series data are stable. Variables using the majority of time series data have been known to be non-stationary time series with unit root. If an unstable time series that does not presuppose the stability of the data is used in the analysis, the R2 value exponentially increases due to the spurious regression phenomenon that disguises relevance seemingly despite the actual irrelevance. Therefore, a unit root test is typically performed to determine the instability of the time series data analyzed. In this study, a traditional method, Augmented Dickey-Fuller (ADF) unit root test and PP (Phillips-Perron) unit root test is conducted. As a result, in Table 4., it has a unit root in the level variable and the time series has no normality. While, the first difference for variables shows that time series have normality because there is no unit root. That is, they are proved to be stable time series.

Table 4. Unit root test

\begin{tabular}{|c|c|c|c|c|}
\hline \multirow{2}{*}{} & \multicolumn{2}{|c|}{ ADF Test } & \multicolumn{2}{c|}{ PP Test } \\
\cline { 2 - 5 } & Level & $1^{\text {st }}$ Diff. & Level & $1^{\text {st }}$ Diff. \\
\hline BTC & -1.41 & $-5.20^{* * *}$ & -1.51 & $-5.11^{* * *}$ \\
\hline ETH & -1.50 & $-5.17^{* * *}$ & -1.58 & $-5.06^{* * *}$ \\
\hline LTC & -1.52 & $-5.68^{* * *}$ & -1.62 & $-5.68^{* * *}$ \\
\hline XRP & -2.44 & $-6.34^{* * *}$ & -2.16 & $-7.92^{* * *}$ \\
\hline XMR & -1.89 & $-6.05^{* * *}$ & -1.82 & $-6.20^{* * *}$ \\
\hline XLM & -2.11 & $-5.45^{* * *}$ & -1.74 & $-4.43^{* * *}$ \\
\hline DASH & -1.80 & $-4.72^{* * *}$ & -1.55 & $-4.64^{* * *}$ \\
\hline DOGE & $-3.87^{* *}$ & $-7.96^{* * *}$ & $-3.79^{* *}$ & $-15.93^{* * *}$ \\
\hline XEM & -2.46 & $-6.55^{* * *}$ & -2.37 & $-9.97^{* * *}$ \\
\hline USDT & $-4.92^{* * *}$ & $-6.50^{* * *}$ & $-3.52^{* *}$ & $-9.73^{* * *}$ \\
\hline & $* * *, * *$ mean $1 \%, 5 \%$ levels & &
\end{tabular}

\subsection{Cointegration test}

When the unit root test results in unstable time series data, it is usually analyzed using stabilized data through the differential process of the data. However, the simple application of this process may lead to errors in the modeling of the long-term equilibrium relationship between variables as well as information loss in the time series. Therefore, a cointegration test is additionally conducted to examine the long-term equilibrium relationship between the variables, which examines the possibility of a long-term equilibrium relationship between the individual level variables diagnosed with unstable time series by a unit root test. This study used the co-integration test method by Johansen (1991) [40], an expanded multivariate time series analysis of DickeyFuller. The multivariate analysis uses vector substitution; when the cointegration relationship is established, the linear combination is stable and longterm equilibrium can be analyzed. As a result, 7 variables within $1 \%$ were considered to have a cointegration relationship, as found to have a long-term equilibrium. The results show that the error is caused by the VAR (Vector Autoregressive Model) when the time series is unstable due to the unit root, and the cointegration exists and represents in long term equilibrium relation. This study is finally analyzed by VECM (Vector Error Correction Models) instead of VAR.

Table 5. Cointegration test

\begin{tabular}{|c|c|c|c|c|}
\hline $\mathrm{H}_{0}$ & Eigenvalue & $\begin{array}{c}\text { Trace } \\
\text { statistics }\end{array}$ & $\begin{array}{c}5 \% \text { Critical } \\
\text { Value }\end{array}$ & Prob. \\
\hline $\mathrm{r}=0$ & 0.998 & 1088.948 & 273.1898 & 0.0000 \\
\hline $\mathrm{r}=1$ & 0.999 & 837.449 & 228.298 & 0.0000 \\
\hline $\mathrm{r}=2$ & 0.991 & 622.822 & 187.470 & 0.0000 \\
\hline $\mathrm{r}=3$ & 0.968 & 439.817 & 150.559 & 0.0000 \\
\hline $\mathrm{r}=4$ & 0.960 & 305.957 & 117.708 & 0.0000 \\
\hline $\mathrm{r}=5$ & 0.877 & 180.348 & 88.804 & 0.0000 \\
\hline $\mathrm{r}=6$ & 0.772 & 98.740 & 63.876 & 0.0000 \\
\hline $\mathrm{r}=7$ & 0.448 & 41.094 & 42.915 & 0.0000 \\
\hline $\mathrm{r}=8$ & 0.294 & 17.947 & 25.872 & 0.3475 \\
\hline $\mathrm{r}=9$ & 0.106 & 4.355 & 12.518 & 0.6903 \\
\hline
\end{tabular}

Trace test indicates 7 cointegrating eqn(s) at the 0.05 level

\subsection{Investor sentiment - VCEM}

The following Table 6. shows, in percentiles, how much each token or coin price was affected by EPU index for each period (1 month). The price of Bitcoin was most affected by US EPU of $5.90 \%$ for one month, followed by Japan EPU (5.60\%). Meanwhile, Singapore's EPU was the least influence on Bitcoin $(0.5 \%)$. Considering that the recent trade volume of 
Bitcoin was the largest in the US, followed by Japan [50], the results implied that the relation between the economic policy uncertainty of each country and the Bitcoin price showed the similar pattern to the trading volume. Among the ten of cryptocurrency analyzed in the study, unlike Bitcoin, 7 tokens or coins (i.e., ETH, DASH, XMR, LTC, XLM, XRP, XEM) were most influenced by Singapore's economic policy uncertainty. This result could be inferred that Singapore's influence was substantial in the cryptocurrency market, because most ICOs were launched in Singapore, in the recent. Many experts of ICOs commonly have mentioned Singapore is a very conducive place to hold an ICO. The rules of Singapore are fair and do not stifle innovation; if the token is not a security, the legal requirements are quite small. It is differentiated with US, which has required relatively strict regulations, following Securities and Exchange Commission's (SEC) negative stance on ICOs. Therefore, Singapore has been attracted to launch for ICOs or STOs(Security Token Offerings) as the best spot and the impact on the overall cryptocurrency market has been expanded. In contrast, Korea had the least impact on DASH, XMR, LTC, and USDT compared to the other countries. In other words, it was found that the influences of Korea's economic policiy on the global cryptocurrency market was rather small. Regarding the difference in the effect of each country's EPU on the price of a single token per 1 month, Bitcoin showed a gap of approximately 5\%, while XRP showed a gap of $18 \%$ or more. Given that the EPU of each country was finally found to have a varying effect on the price volatility of each token or coin, it could be concluded that individual investor sentiment affected trading behaviors.

Table 6. Results of VECM

\begin{tabular}{|c|c|c|c|c|c|c|c|c|c|c|}
\hline & BTC & ETH & DASH & XMR & LTC & USDT & XLM & XRP & XEM & DOGE \\
\hline US & 5.90 & 4.04 & 6.32 & 3.48 & 7.18 & 10.93 & 2.79 & 1.74 & 10.33 & 1.46 \\
\hline Japan & 5.60 & 0.23 & 6.86 & 7.97 & 5.28 & 0.46 & 0.11 & 0.41 & 0.37 & 17.42 \\
\hline Singapore & 0.54 & 10.04 & 7.45 & 9.98 & 11.37 & 0.13 & 8.26 & 18.57 & 15.56 & 0.14 \\
\hline China & 4.35 & 1.45 & 4.09 & 4.60 & 6.05 & 4.78 & 0.98 & 2.78 & 6.43 & 17.80 \\
\hline Korea & 0.92 & 0.73 & 0.82 & 2.51 & 1.14 & 0.01 & 0.78 & 0.44 & 0.87 & 0.89 \\
\hline Europe & 1.56 & 0.34 & 3.74 & 4.42 & 1.80 & 2.77 & 3.45 & 0.18 & 0.01 & 0.20 \\
\hline Adj. $R$-squared & 84.2 & 94.0 & 94.1 & 94.6 & 91.6 & 83.7 & 95.1 & 95.8 & 94.7 & 79.6 \\
\hline
\end{tabular}

\section{Research contributions}

This study identified a significant relationship between investor sentiment and cryptocurrency market price. It can be concluded that a large number of traders make their trading decisions based on their sentiment rather than information about cryptocurrencies. Additionally, we identified stronger degree of information asymmetry of cryptocurrency market compared with a stock market. Based on our study results, it can be suggested that the current cryptocurrency market influenced by privileged information strongly and is in a relatively high-risk environment than a stock market.

This study provides a foundation to understand the cryptocurrency market. The results of this study confirm that the cryptocurrency market has information asymmetry similar to the traditional stock market. It indicates the cryptocurrency market has formed a market inefficiency due to information inefficiency. Efficient market means market information is distributed equally to the all market participants [41]. In an information efficient market, investors cannot obtain abnormal returns using privileged information. As prior study pointed out information inefficiency in a main cause of a market inefficiency [46, 47]. Based on our study findings, cryptocurrency market is an inefficient market stems from information asymmetry so that traders, who own privileged information, can obtain excess profits.

Information asymmetry remains unsolved in the market for a long time although it is an inherently important issue that may lead to moral hazard due to reverse selection and consequential market failure [49]. The best way to mitigate information asymmetry is that individual investors try to obtain as much information as possible and conduct transactions based on the collected information. However, it is costly for an individual to obtain information, and the quality and accuracy of acquired information cannot 
always be guaranteed. Above all, it is impossible to obtain sufficient information to ensure the satisfaction of transaction decision-making. Therefore, in the current stock market, disclosure systems, such as Corporate Disclosure, Regulation Fair Disclosure and, Financial Information Disclosure, have been implemented to mitigate information asymmetry. The similar disclosure systems for the cryptocurrency market need to be adopted as well. It suggests the need for a disclosure system to provide information to investors, such as the SEC's Edgar in the traditional market. Although there are ICOs that provide information on the issuance of tokens or coins, they are dependent on the type and volume of announced information are not sufficient to determine the trading behaviors of investors. Thus, to improve the current ICOs, enacting various disclosure systems is necessary to mitigate information asymmetry. Moreover, the current cryptocurrency exchanges, that identify a trader only with a wallet address after the KYC (Know Your Client) procedure, are not able to detect improper acts such as unfair insider trading. Considering this problem, the mandatory disclosure systems will be a useful solution to mitigate information asymmetry in the overall cryptocurrency market.

This study identified the influence of economic policy uncertainty on cryptocurrency price. The study results represent that investor sentiments are significantly affecting cryptocurrency price. While sentiment-based investments result in significant price volatility, the market must be properly regulated so that it cannot be invested only in dependence on sentiment

To this end, public information and policies should be provided to the market so that the investment based on the sentiment can be properly managed.

\section{Limitations \& further research}

Among the over 2,000 types of cryptocurrencies, the results of this study are based on only ten major ones. To generalize our study results, additional tests need to be carried out with a greater number of cryptocurrencies. In this study, there is also a limitation that information asymmetry is estimated based on only transaction data which cannot control variety of factors affecting price volatility of cryptocurrency.

Market signaling theory assuming information asymmetry in the market explains that an investor with more information reduces the level of information asymmetry by transferring relevant information as 'signals' to another investor with less information in order to maximize his or her profit $[44,45]$. Thus, it is necessary to pay attention to 'signals' in the cryptocurrency market in the future. Identifying when and how the 'market signals' occur in the cryptocurrency market can help mitigate information asymmetry among investors through the signals.

As the cryptocurrency studies are still at an early stage, there is little empirical research on the factors affecting cryptocurrency price volatility. Therefore, multi-dimensional studies are necessary to clarify factors influencing the price fluctuation of cryptocurrency from perspectives in the future. In addition, future studies need to examine whether each token or coin price will form comovement with the others in considering that the price changes in S\&P500, DXY, gold and Bitcoin are found to show a similar reaction.

\section{References}

[1] Mai, F., et al., "How does social media impact Bitcoin value? A test of the silent majority hypothesis", Journal of Management Information Systems, 2018. 35(1), pp. 19-52.

[2] Javakhadze, D., S.P. Ferris, and N. Sen, "An international analysis of dividend smoothing", Journal of Corporate Finance, 2014. 29, pp. 200-220.

[3] Wei, W.C., Essays on Information Asymmetry and Price Impact in Market Microstructure. 2013.

[4] French, K.R. and R. Roll, "Stock return variances: The arrival of information and the reaction of traders", Journal of financial economics, 1986. 17(1), pp. 5-26.

[5] Nofsinger, J.R., "The impact of public information on investors. Journal of Banking and Finance", 2001. 25(7), p. 1339-1366.

[6] Devos, J., H. Van Landeghem, and D. Deschoolmeester, "Outsourced information systems failures in SMEs: a multiple case study", Electronic Journal of Information System Evaluation, 2008. 11(2), pp. 73-84.

[7] Foster, F.D. and S. Viswanathan, "Can speculative trading explain the volume-volatility relation?", Journal of Business and Economic Statistics, 1995. 13(4), pp. 379-396.

[8] Chen, G.m., M. Firth, and O.M. Rui, "The dynamic relation between stock returns, trading volume, and volatility", Financial Review, 2001. 36(3), pp. 153-174.

[9] Grundy, B.D. and H. Li, "Investor sentiment, executive compensation, and corporate investment", Journal of Banking and Finance, 2010. 34(10), pp. 2439-2449.

[10] Easley, D., et al., "Liquidity, information, and infrequently traded stocks", The Journal of Finance, 1996. 51(4), pp. 1405-1436.

[11] Dawson, G.S., R.T. Watson, and M.-C. Boudreau, "Information asymmetry in information systems consulting: toward a theory of relationship constraints", Journal of Management Information Systems, 2010. 27(3), pp. 143-178.

[12] Akerlof, G.A., "The Market for" Lemons": Quality Uncertainty and the Market Mechanism", 84Q. J. ECON, 1970. 488, pp. 489-90. 
[13] Jamal, K. and N.E. Bowie, "Theoretical considerations for a meaningful code of professional ethics", Journal of business ethics, 1995. 14(9), pp. 703-714.

[14] Lindman, J., V.K. Tuunainen, and M. Rossi. "Opportunities and Risks of Blockchain TechnologiesA Research Agenda", Proceedings of the 50th Hawaii International Conference on System Sciences, 2017.

[15] Glaser, F. "Pervasive Decentralisation of Digital Infrastructures: A Framework for Blockchain enabled System and Use Case Analysis", Proceedings of the 50th Hawaii International Conference on System Sciences, 2017.

[16] Diamond, D.W. and R.E. Verrecchia, "Disclosure, liquidity, and the cost of capital", The journal of Finance, 1991. 46(4) pp. 1325-1359.

[17] Baiman, S. and R.E. Verrecchia, "The relation among capital markets, financial disclosure, production efficiency, and insider trading", Journal of accounting research, 1996. 34(1), pp. 1-22.

[18] Leuz, C. and R.E. Verrecchia, "The economic consequences of increased disclosure", 1999.

[19] Park, J.-W. and S.-B. Yang, "An Empirical Study on Factors Affecting Blockchain Start-ups' Fundraising via Initial Coin Offerings", ICIS proceedings 2018.

[20] Zetzsche, D.A., et al., "The ICO Gold Rush: It's a scam, it's a bubble, it's a super challenge for regulators", University of Luxembourg Law Working Paper, 2017(11), pp. 17-83.

[21] Easley, D., S. Hvidkjaer, and M. O'hara, "Factoring information into returns", Journal of Financial Quantitative Analysis, 2010. 45(2), pp. 293-309.

[22] Shleifer, A., Inefficient markets: An introduction to behavioural finance. 2000: OUP Oxford.

[23] Barberis, N. and A. Shleifer, "Style investing", Journal of financial Economics, 2003. 68(2), pp. 161-199.

[24] Chang, A., et al., An Overview of Investor Sentiment in Stock Market. 2015.

[25] Lemmon, M. and E. Portniaguina, "Consumer confidence and asset prices: Some empirical evidence", The Review of Financial Studies, 2006. 19(4), pp. 1499-1529.

[26] Baker, M. and J. Wurgler, "Investor sentiment and the cross-section of stock returns", The journal of finance, 2006. 61(4), pp. 1645-1680.

[27] Kumari, J. and J. Mahakud, "Does investor sentiment predict the asset volatility? Evidence from emerging stock market India", Journal of Behavioral and Experimental Finance, 2015. 8, pp. 25-39.

[28] Brown, G.W. and M.T. Cliff, "Investor sentiment and asset valuation", The Journal of Business, 2005. 78(2), pp. 405-440.

[29] Liu, Z., et al., "Can economic policy uncertainty help to forecast the volatility: A multifractal perspective. Physica A", Statistical Mechanics its Applications, 2017. 482, pp. 181-188.

[30] Baker, S.R., N. Bloom, and S.J. Davis, "Measuring economic policy uncertainty", The quarterly journal of economics, 2016. 131(4), pp. 1593-1636.

[31] Brogaard, J. and A. Detzel, "The asset-pricing implications of government economic policy uncertainty", Management Science, 2015. 61(1), pp. 318.

[32] Shahzad, S.J.H., et al., "Can economic policy uncertainty and investors sentiment predict commodities returns and volatility?", Resources Policy, 2017. 53, pp. 208-218.

[33] Wang, G.-J., et al., "When Bitcoin meets economic policy uncertainty (EPU): Measuring risk spillover effect from EPU to Bitcoin", Finance Research Letters, 2018.

[34] Demir, E., et al., "Does economic policy uncertainty predict the Bitcoin returns? An empirical investigation", Finance Research Letters, 2018. 26, pp. 145-149.

[35] Easley, D., S. Hvidkjaer, and M. O'hara, "Is information risk a determinant of asset returns?", The journal of finance, 2002. 57(5), pp. 2185-2221.

[36] Tay, A., et al., "Using high-frequency transaction data to estimate the probability of informed trading", Journal of Financial Econometrics, 2009. 7(3), pp. 288-311.

[37] Cubadda, G., "Common cycles in seasonal nonstationary time series", Journal of Applied Econometrics, 1999. 14(3), pp. 273-291.

[38] Gunes, S., Functional income distribution in Turkey: a cointegration and VECM analysis. Journal of Economic and social Research, 2007. 9(2), pp. 23-36.

[39] Dritsakis, N., "Cointegration analysis of German and British tourism demand for Greece", Tourism management, 2004. 25(1), pp. 111-119.

[40] Johansen, S., "Estimation and hypothesis testing of cointegration vectors in Gaussian vector autoregressive models. Econometrica",Journal of the Econometric Society, 1991, pp. 1551-1580.

[41] Fiala, P., "Information sharing in supply chains", Omega, 2005. 33(5), pp. 419-423.

[42] European Central Bank, "Virtual Currency Schemes", Oct. 2012.

[43] Weissensteiner, A., "Correlated noise: Why passive investment might improve market efficiency", Journal of Economic Behavior \& Organization 2019. 158, pp. $158-172$.

[44] Connelly, B.L., et al., "Signaling theory: A review and assessment", Journal of management, 2011. 37(1), pp. 39-67.

[45] Spence, M., "Job market signaling, in Uncertainty in Economics", 1978, Elsevier. pp. 281-306.

[46] Easley, D., M.L. De Prado, and M. O'Hara, "The microstructure of the flash crash: Flow toxicity, liquidity crashes and the probability of informed trading", Journal of Portfolio Management, 2011. 37(2), pp. 118-128.

[47] Moss, T.W., D.O. Neubaum, and M. Meyskens, "The effect of virtuous and entrepreneurial orientations on microfinance lending and repayment: A signaling theory perspective", Entrepreneurship Theory and Practice, 2015. 39(1), pp. 27-52.

[48] Dey, M.K. and B. Radhakrishna, Informed trading, institutional trading, and spread. Journal of Economics and Finance, 2015. 39(2), pp. 288-307.

[49] Mavlanova, T., R. Benbunan-Fich, and M. Koufaris, "Signaling theory and information asymmetry in online 
commerce", Information \& Management, 2012. 49(5), pp. 240-247.

[50] The Block, "U.S. leads the world in crypto interest, but factoring population data shrinks the gap", https://www.theblockcrypto.com/tiny/u-s-leads-theworld-in-crypto-interest-but-factoring-populationdata-shrinks-the-gap, 2019.05.31.

[51] Zhou, R. T., \& Lai, R. N. Herding and information based trading. Journal of Empirical Finance, 2009. 16(3), pp. 388-393.

[52] Yelowitz, A., \& Wilson, M., Characteristics of Bitcoin users: an analysis of Google search data. Applied Economics Letters, 2015. 22(13), pp. 1030-1036. 